\title{
Simple and Sensitive RP-HPLC and UV Spectroscopic Methods for the Determination of Remogliflozin Etabonate in Pure and Pharmaceutical Formulations
}

\author{
(1) Nandeesha ITIGIMATHA 1 , (1) Kailash S. CHADCHAN², (1) Basappa C. YALLUR ${ }^{1}$, (1) Manjunatha D. HADAGALI* \\ 1Visvesvaraya Technological University, Ramaiah Institute of Technology, Department of Chemistry, Bangalore, India \\ 2BLDEA's V.P. Dr. P.G. Halakatti College of Engineering and Technology, Department of Chemistry, Karnataka, India \\ 3Davangere University, Department of Studies in Chemistry, Karnataka, India
}

\begin{abstract}
Simple, novel and selective reverse phase-high performance liquid chromatography (RP-HPLC) and ultraviolet (UV) spectroscopic methods have been developed and optimized for the determination of remogliflozin etabonate (RMZ) in bulk and dosage forms. In the HPLC method, the principal peak and internal standard peak were eluted separately at different retention times (RT) with the chromatographic conditions such as, mobile phase consisting of $0.02 \mathrm{M}$ ammonium acetate buffer ( $\mathrm{pH}$ was adjusted to 4.0 by $1.0 \mathrm{M}$ ortho phosphoric acid), acetonitrile and tetrahydrofuran in the ratio 50:45:05, respectively (v/v) and the stationary phase used was $\mathrm{C18}, 5 \mu \mathrm{m}, 4.6 \mathrm{~mm} \times 250 \mathrm{~mm}$ kromasil column. The flow rate was $2.0 \mathrm{~mL} \mathrm{~min}^{-1}$, sample injection volume was $10 \mu \mathrm{L}$, and the wavelength of detection was fixed at $228 \mathrm{~nm}$. In case UV spectroscopic method, the RMZ was diluted with pure ethanol. The RMZ showed a maximum absorbance at $228 \mathrm{~nm}$. Hence throughout analysis $228 \mathrm{~nm}$ was used for the determination of RMZ. The RT of RMZ and internal standard, atorvastatin (ATST) were $6.2 \mathrm{~min}$ and $7.0 \mathrm{~min}$, respectively. The resolution between the peaks was found to be more than 2.0. The total run time was fixed at $10 \mathrm{~min}$. The linearity range for RP-HPLC method was found to be $10 \mu \mathrm{g} \mathrm{mL}^{-1}$ to $50 \mu \mathrm{g} \mathrm{mL}{ }^{-1}$, at a fixed concentration of ATST. The linearity range for the UV spectroscopic method was found to be in the range of 100 to $250 \mu g \mathrm{~mL}^{-1}$. Regression coefficients (R2) were found above 0.999 for both of the techniques. The limit of detection and quantification for RMZ were found to be $1.0 \mu \mathrm{g}$ $\mathrm{mL}^{-1}$ and $3.5 \mu \mathrm{g} \mathrm{mL} \mathrm{m}^{-1}$ respectively, in RP-HPLC method and $10.0 \mu \mathrm{g} \mathrm{mL}^{-1}$ and $40 \mu \mathrm{g} \mathrm{mL} \mathrm{L}^{-1}$, respectively, in UV spectroscopic method. The developed methods were found to be simple, accurate, reproducible, and precise. The RMZ can be analyzed in dual techniques, i.e., chromatographic and UV spectroscopic methods for its routine analysis.
\end{abstract}

Key words: Remogliflozin etabonate, RP-HPLC, UV spectroscopy, bulk and dosage forms

\section{INTRODUCTION}

Remogliflozin etabonate (RMZ) (Figure 1) chemically known as (5-methyl-4-[4-(1-methylethoxy) benzyl]-1-(1-methylethyl)$1 H$-pyrazol-3-yl 6-0-(ethoxycarbonyl)- $\beta$-D glucopyranoside), belongs to the gliflozin category. It is a pro-drug of gliflozin, which is used mainly for the non-alcoholic steatohepatitis and type 2 diabetes. RMZ helps reduce the sodium-glucose, transport proteins, and it is accountable for glucose reinclusion in the kidney. ${ }^{12}$
Thorough literature review revealed that few methods were developed and validated by different analytical instruments for the determination of RMZ1.3-10 An analytical method has been developed by ultra-performance liquid chromatography (UPLC) in bulk and in formulations for the simultaneous estimation of RMZ and metformin hydrochloride. The mobile phase used was phosphate buffer $(\mathrm{pH}: 4.5)$ and acetonitrile in the ratio $60: 40 \mathrm{v} / \mathrm{v}$.' An ultraviolet (UV) spectrophotometric method was developed for the simultaneous estimation of empagliflozin 


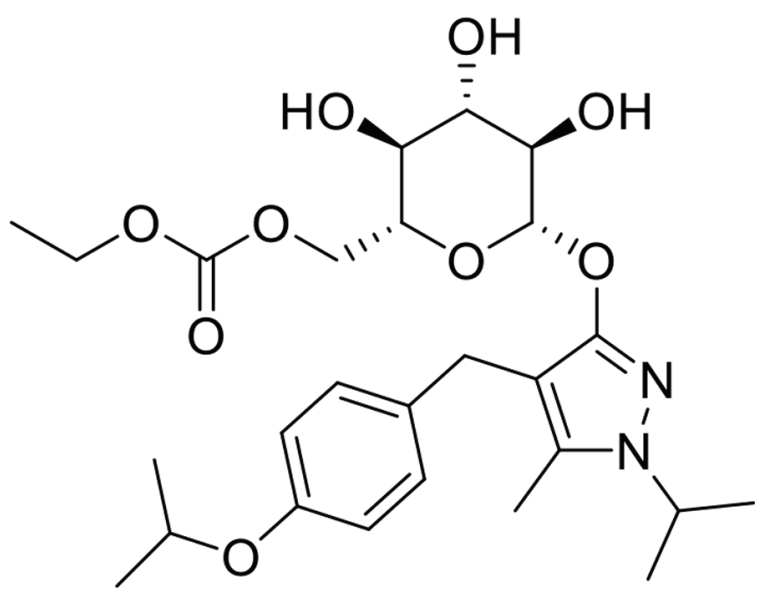

Figure 1. Chemical structure of RMZ

and metformin hydrochloride in bulk and dosage forms. ${ }^{3}$ The method showed that there were two methods, i.e. $A$ and $B$, in method $A$ the absorption was measured at $272 \mathrm{~nm}$ and $234 \mathrm{~nm}$ for empagliflozin and metformin hydrochloride, respectively. Method B used the absorbance ratio ( $Q$-analysis), in which the absorbance was measured at $254 \mathrm{~nm}$ and $226 \mathrm{~nm}$ for empagliflozin and metformin hydrochloride, respectively. ${ }^{3} \mathrm{~A}$ liquid chromatographic method was developed and validated for simultaneous estimation of metformin, pioglitazone, and glimepiride in dosage forms. ${ }^{4}$ This method determined the diabetic drugs except RMZ. reverse phase-high performance liquid chromatography (RP-HPLC) method has been developed for the simultaneous determination of dapagliflozin and saxagliptin in the bulk and pharmaceutical dosage forms. ${ }^{5}$ Stability indicating HPLC method was developed for the determination of saxagliptin and metformin in the bulk forms. ${ }^{6}$ A RP-HPLC method was developed and validated for the simultaneous determination of metformin and saxagliptin in the formulations. ${ }^{7}$ The simultaneous estimation of metformin hydrochloride and canagliflozin by stability-indicating RPHPLC method was developed by Kommineni et al. ${ }^{8}$ An assay method was developed and validated for simultaneous determination of metformin hydrochloride and canagliflozin by RP-HPLC instrument. ${ }^{9}$ Ayoub developed spectrophotometric and chemometric methods for the simultaneous determination of empagliflozin and metformin in the pharmaceutical formulations. ${ }^{10}$ An UV derivative spectrophotometric method was developed for the simultaneous determination of metformin and remogliflozin by Attimarad et al.1 A thorough statistical data analysis of the reported methods and proposed methods are given in Table 1. The reported methods were not simple in a way that they have a long run time or having a complicated mobile phase. The UPLC instrument is sophisticated, but expensive so that the small-scale industries and laboratories cannot afford. Keeping these points in view, we proposed the RP-HPLC and UV spectroscopic methods for the determination of RMZ in bulk and formulations. The results of the proposed methods indicated that the HPLC and UV spectroscopic methods for the determination of RMZ in pure and dosage forms are simple, accurate and rugged. The RP-HPLC method was developed with atorvastatin (ATST) as an internal standard. For the proposed UV spectroscopic method, the absorbance was measured at $228 \mathrm{~nm}$. Both the methods were validated according to the $\mathrm{ICH}$ guidelines. ${ }^{12}$

\section{MATERIALS AND METHODS}

\section{Instruments}

The proposed method was developed and validated using Shimadzu prominence-i HPLC, which consists of an autoinjector, UV detector with a deuterium lamp as the source of light and a quaternary pump. The output signal and chromatographic data were processed using lab solution software. Eutech $\mathrm{pH}$ meter was used for measuring the $\mathrm{pH}$ of the buffer solution. An ultrasonic sonicator bath was used to degas the solvents and a nylon membrane of $0.45 \mu \mathrm{m}$ filter paper was used for filtration.

For UV-spectroscopic method, agilent UV-visible spectrophotometer (carry 60 model), which consists of a deuterium lamp as a source of light was employed. The spectra were monitored and processed by Win lab software. The solvents used in the experiment were degassed using an ultrasonic bath.

\section{Chemicals and reagents}

RMZ and ATST compounds ( $>98 \%$ purity) were provided by Karnataka Antibiotics and Pharmaceutical Ltd. (Bengaluru, India) as gift samples. HPLC grade ammonium acetate, tetrahydrofuran (THF), and ethanol (99.9\% purity) were purchased from SD Fine-Chem Ltd. (India). Acetonitrile and ortho-phosphoric acid were procured from Merk Ltd. (India). The ultra-purified water was prepared by Siemens purifier instrument (India). Column Kromasil, C18, $5 \mu \mathrm{m}, 4.6 \mathrm{~mm}$ x 250 $\mathrm{mm}$, was obtained from Waters Ltd. for the UV spectroscopic method development, pure ethanol was used as the diluent.

\section{Preparation of mobile phase, standard solutions and dilutions}

The mobile phase was prepared by mixing $0.02 \mathrm{M}$ ammonium acetate buffer ( $\mathrm{pH}$ adjusted to 4.0 using $1.0 \mathrm{M}$ ortho-phosphoric acid), acetonitrile and THF, in the ratio of 50:45:05, respectively $(\mathrm{v} / \mathrm{v} / \mathrm{v})$. The standard solution was prepared by transferring accurately weighed $100 \mathrm{mg}$ RMZ to $100 \mathrm{~mL}$ standard flask, followed by making up to the mark with the mobile phase. The concentration of the resultant stock solution was $1000 \mu \mathrm{g} \mathrm{mL}-1$. From this stock solution, $0.1 \mathrm{~mL}$ solution was pipetted out into another $100 \mathrm{~mL}$ standard flask and made up to the mark with the mobile phase. The concentration of the resulting working standard solution was $1.0 \mu \mathrm{g} \mathrm{mL}^{-1}$. Similarly, to obtain a linearity graph, the stock solution was diluted to get the concentrations ranging from 10 to $50 \mu \mathrm{g} \mathrm{mL}-1$. A $30 \mu g \mathrm{~mL}^{-1}$ of internal standard (ATST) was prepared in the mobile phase. For the development of the UV spectroscopic method, a similar procedure was followed. The standard stock solution and working standard solutions were prepared by taking ethanol as the diluent. 


\section{Chromatographic conditions}

The mobile phase was composed of a buffer solution consisting of $0.02 \mathrm{M}$ ammonium acetate buffer ( $\mathrm{pH}$ adjusted to 4.0 with 1.0 $\mathrm{M}$ ortho-phosphoric acid), acetonitrile and THF in the ratio of 50:45:05, respectively ( $\mathrm{v} / \mathrm{v} / \mathrm{v})$. The flow rate of the mobile phase was maintained at $1.0 \mathrm{~mL} \mathrm{~min}{ }^{-1}$. The column temperature was kept at $25^{\circ} \mathrm{C}$ and the stationary phase was kromasil column (C18, $5 \mu \mathrm{m}, 4.6 \mathrm{~mm} \times 250 \mathrm{~mm}$ ). The wavelength of detection was fixed at $228 \mathrm{~nm}$. The sample injection volume was $10 \mu \mathrm{L}$. The retention times (RT) of RMZ and ATST were 6.2 and 7.0 min, respectively.

\section{Table 1. Comparison of the statistical data of the reported methods and proposed methods}

\begin{tabular}{|c|c|c|c|c|}
\hline Ref. no. & Analytical method & Drug(s) analyzed & Result(s) & Remarks \\
\hline 3 & $\begin{array}{l}\text { UV- } \\
\text { spectrophotometric }\end{array}$ & $\begin{array}{l}\text { Simultaneous determination of } \\
\text { emphagifolizine and metformin } \\
\text { hydrochloride }\end{array}$ & $\begin{array}{l}\text { Linearity range: } 5-25 \text { and } 2-12 \mu \mathrm{gL}^{-1} \\
\text { LOD: Not available } \\
\text { LOQ: Not available }\end{array}$ & $\begin{array}{l}\text { Glifolizine pro-drug used } \\
\text { for determination with } \\
\text { metformin } \\
\text { Not included RMZ }\end{array}$ \\
\hline 4 & $\begin{array}{l}\text { Liquid } \\
\text { chromatography }\end{array}$ & $\begin{array}{l}\text { Simultaneous determination } \\
\text { of RMZ and metformin } \\
\text { hydrochloride }\end{array}$ & $\begin{array}{l}\text { Linearity range: } 1-20 \mu \mathrm{g} \mathrm{mL}^{-1} \\
\text { LOD: } 0.180 \mu \mathrm{gL}^{-1} \\
\text { LOQ: } 0.560 \mu \mathrm{mL}^{-1}\end{array}$ & Narrow linearity range \\
\hline 5 & RP-HPLC & $\begin{array}{l}\text { Simultaneous determination of } \\
\text { dapagliflozin and saxagliptin }\end{array}$ & $\begin{array}{l}\text { Linearity range: } 20-70 \text { and } 20-70 \\
\text { LOD: } 0.109 \text { and } 0.58 \mu \mathrm{gL} \mathrm{LL}^{-1} \\
\text { LOQ: } 0.332 \text { and } 1.77 \mu \mathrm{gL}^{-1}\end{array}$ & $\begin{array}{l}\text { Glifolizine pro-drug used for } \\
\text { determination } \\
\text { Not included RMZ }\end{array}$ \\
\hline
\end{tabular}

Linearity range: $10-50$ and $20-100 \mu \mathrm{g}$

$\mathrm{mL}^{-1}$

LOD: 0.016 and $0.14 \mu \mathrm{g} \mathrm{mL}^{-1}$

LOQ: 0.048 and $0.42 \mu \mathrm{g} \mathrm{mL}-1$

Metformin hydrochloride and

sitagliptin phosphate

Linearity range: $25-150$ and 2.5-15 $\mu \mathrm{g}$

$\mathrm{mL}^{-1}$

LOD: 0.17 and $0.50 \mu \mathrm{gL}^{-1}$

LOQ: 0.01 and $0.50 \mu \mathrm{g} \mathrm{mL}^{-1}$

Metformin hydrochloride and canagliflozin

Metformin hydrochloride and canagliflozin

Linearity range: $25-150$ and 2.5-15 $\mu \mathrm{g}$

$\mathrm{mL}^{-1}$

LOD: 0.134 and $0.124 \mu \mathrm{mL}^{-1}$ LOQ: 0.406 and $0.376 \mu \mathrm{gL}^{-1}$

Linearity range:

LOD: 0.20 and $0.19 \mu \mathrm{g} \mathrm{mL}^{-1}$ LOQ: 0.59 and $0.58 \mu \mathrm{g} \mathrm{mL}^{-1}$

Other than RMZ drug determined

Other than RMZ drug determined

Other than RMZ drug determined

Other than RMZ drug determined

Linearity range: $1-20$ and $2.5-35 \mu \mathrm{gL}^{-1}$ LOD: 0.180 and $0.660 \mu \mathrm{g} \mathrm{mL}^{-1}$ LOQ: 0.560 and $1.850 \mu \mathrm{gL}^{-1}$

Derivative method

UV derivative

11 Spectrophotometric Metformin and RMZ Methods

\section{HPLC method}

Linearity range: $10-50 \mu \mathrm{gL}^{-1}$

LOD: $1.00 \mu \mathrm{g} \mathrm{mL}^{-1}$

LOQ: $3.50 \mu \mathrm{g} \mathrm{mL}^{-1}$

Proposed RP-HPLC and UV methods spectroscopic
Remogliflozin etabonate

\section{UV spectroscopic method} Linearity range :100-250 $\mu \mathrm{g} \mathrm{mL}^{-1}$ LOD: $10.00 \mu \mathrm{g} \mathrm{mL}^{-1}$ LOQ: $40.00 \mu \mathrm{g} \mathrm{mL}^{-1}$ $R^{2}: 0.999$

UPLC: Ultra-performance liquid chromatography, UV: Ultraviolet, RP-HPLC: Reverse phase-high performance liquid chromatography, RMZ: Remogliflozin etabonate, LOD: Limit of detection, LOQ: Limit of quantification 


\section{Spectroscopic conditions}

The stock solution of RMZ was scanned between $200-400$ $\mathrm{nm}$, which showed maximum absorbance at $228 \mathrm{~nm}$ by a UV spectrophotometer. Further, to confirm the analysis, different concentrations of RMZ drug solutions were scanned. The source of the detector contained a deuterium lamp and quartz cuvettes were used as sample holders.

\section{RESULTS}

\section{Method development}

The mobile phase equilibrium was primarily conceded using a stationary phase column (kromasil). Initially, the mobile phase used for different trials was ammonium acetate and acetonitrile with different concentrations and ratios. In another experiment, $0.02 \mathrm{M}$ ammonium acetate buffer ( $\mathrm{pH}$ adjusted to 4.0 with $10 \%$ dilute acetic acid) and methanol in the ratio 50:50 was tried. In this trial, it was possible to detect peaks, but elution was inaccurate. Further trials were carried out with different ratios of $0.02 \mathrm{M}$ ammonium acetate ( $\mathrm{pH}: 4.0$ ), acetonitrile and THF. However, with the mobile phase of ratio 50:45:05, respectively $(\mathrm{v} / \mathrm{v} / \mathrm{v})$, the peaks of RMZ and ATST internal standard were eluted with good shape and resolution. Hence, the mobile phase of the ratio 50:45:05 was considered for the entire RP-HPLC method development and validation. The flow rate of the mobile phase was kept at $1.0 \mathrm{~mL} \mathrm{~min}$. With these experimental trials, the resulting peaks were eluted as satisfactory, in accordance with $\mathrm{ICH}$ guidelines. In this method, the total run time was 10 min for the elution of both peaks. For detecting the eluted peaks, the wavelength of detection was fixed at $228 \mathrm{~nm}$. The proposed method was validated as per the ICH guidelines."

The UV spectroscopic method development was carried out by scanning the RMZ drug in the UV region ranging between 200 $\mathrm{nm}$ to $380 \mathrm{~nm}$ at different concentrations in the scan mode. The RMZ showed a maximum absorbance at $228 \mathrm{~nm}$. Hence, $\lambda_{\max }$ of $228 \mathrm{~nm}$ was fixed for the entire method development process. The RMZ solution was subsequently diluted with the ethanol to obtain different concentrations according to the desired parameters. All the obtained results are satisfactory and are tabulated in Table 2. The parameters were well within the limits as specified in the ICH guidelines." For the proposed research, the ethics committee approval is not required. Since we have not used any matrices for human beings and animals. The statistical data (obtained results of all parameters) was revealed in tables form with respect to the parameter results.

\section{System suitability}

The proposed HPLC method has consistent RT for RMZ and ATST at 6.2 and $7.0 \mathrm{~min}$, respectively. There were no changes in the RT throughout the analysis. The percentage of relative standard deviation \% (RSD) from six individual spikes (analytes) was found to be less than $2.0 \%$ at least concentrations, i.e., $0.74 \%$ and $0.82 \%$ for the RMZ and ATST, respectively. The system suitability data are tabulated in Table 2 and the characteristic chromatograms are shown in Figure 2A. The resultant data indicate that the developed method has good sensitivity for RMZ. The limit of detection (LOD) and limit of quantification (LOQ) was found to be $1.0 \mu \mathrm{g} \mathrm{mL}^{-1}$ and $3.5 \mu \mathrm{g} \mathrm{mL}^{-1}$, respectively, and $\mathrm{S} / \mathrm{N}$ ratios found for $\mathrm{LOD}$ and $\mathrm{LOQ}$ were 6.5 and 21 , respectively. The results were found to be satisfactory and within the limits as shown in Table 3.

In the case of the UV spectroscopic method, the percentage of RSD was found to be less than $2.0 \%$. The LOD and LOQ were found to be $10 \mu \mathrm{g} \mathrm{mL}^{-1}$ and $40 \mu \mathrm{g} \mathrm{mL}^{-1}$ respectively. The results were found to be satisfactory and are tabulated in Table 3.

\begin{tabular}{llll}
\multicolumn{4}{l}{ Table 2. RP-HPLC system suitability parameters } \\
Parameter & RMZ & ATST & Limit \\
\hline Number of theoretical plates & 6269 & 6465 & NLT $^{*} 2000$ \\
\hline Retention time $\left(t_{R}\right)$ in min & 6.10 & 7.00 & - \\
\hline Resolution & - & 2.90 & NLT $^{*} 2.0$ \\
\hline Peak asymmetry $\left(\mathrm{A}_{S}\right)$ & 1.06 & 1.09 & NMT $^{* *} 2.0$ \\
\hline \% RSD & 0.74 & 0.82 & NMT $^{* *} 2.0$ \\
\hline
\end{tabular}

${ }^{*}$ NLT: Not less than, ${ }^{* *}$ NMT: Not more than, ${ }^{*}$ Average of 6 injections, RP-HPLC: Reverse phase-high performance liquid chromatography, RMZ: Remogliflozin etabonate, ATST: Atorvastatin, RSD: Relative standard deviation

\section{Table 3. Calibration curve results, limit of detection and limit of} quantification

\begin{tabular}{lll} 
Parameter & RP-HPLC & $\begin{array}{l}\text { UV- } \\
\text { spectroscopy }\end{array}$ \\
\hline Linear dynamic range $\left(\mu \mathrm{g} \mathrm{mL}^{-1}\right)$ & $10-50$ & $100-250$ \\
\hline Regression equation $\left(Y^{a}\right)$ & - & - \\
\hline Slope $(b)$ & 0.028 & 0.003 \\
\hline Intercept (c) & -0.015 & -0.131 \\
\hline Correlation coefficient $(r)$ & 0.999 & 0.999 \\
\hline LOD ( $\left.\mu g \mathrm{~mL}^{-1}\right)$ & 1.00 & 10.00 \\
\hline LOQ $\left(\mu \mathrm{g} \mathrm{mL}^{-1}\right)$ & 3.50 & 40.00 \\
\hline$\%$ RSD* & 0.24 & 0.92
\end{tabular}

$Y^{a}=b X+c$, where $X$ is concentration of drug in $\mu g \mathrm{~mL}^{-1}$, *Average of 6 injections and/or scans. RP-HPLC: Reverse phase-high performance liquid chromatography, LOD: Limit of detection, LOQ: Limit of quantification, UV: Ultraviolet, RSD: Relative standard deviation

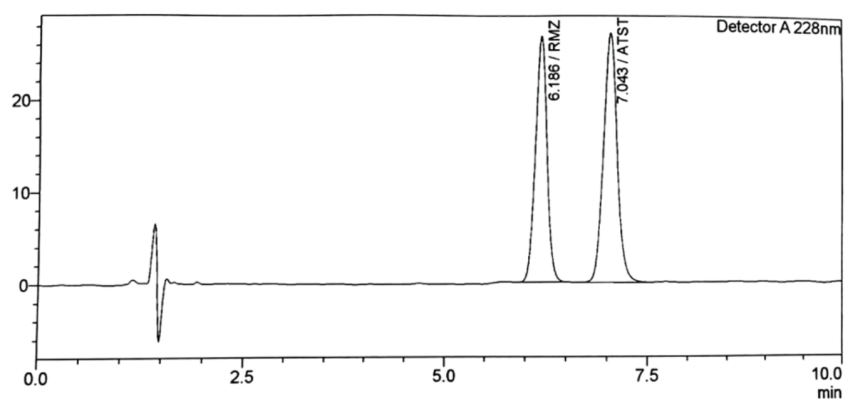

Figure 2A. A typical HPLC chromatogram of the RMZ and ATST 


\section{Linearity}

In UV spectroscopic method development, five different concentrations of RMZ solutions ranging from 100 to $250 \mu \mathrm{g} \mathrm{mL}^{-1}$ were scanned using a UV spectrophotometer. RMZ is absorbed at a maximum absorbance at $228 \mathrm{~nm}$. The resulting linearity overlay spectra are shown in Figure $2 \mathrm{~B}$ and the linearity graph was plotted by the absorbance against the concentration of $R M Z$ and the regression coefficient $\left(R^{2}\right)$ was found to be more than 0.999. The results are tabulated in Table 3.

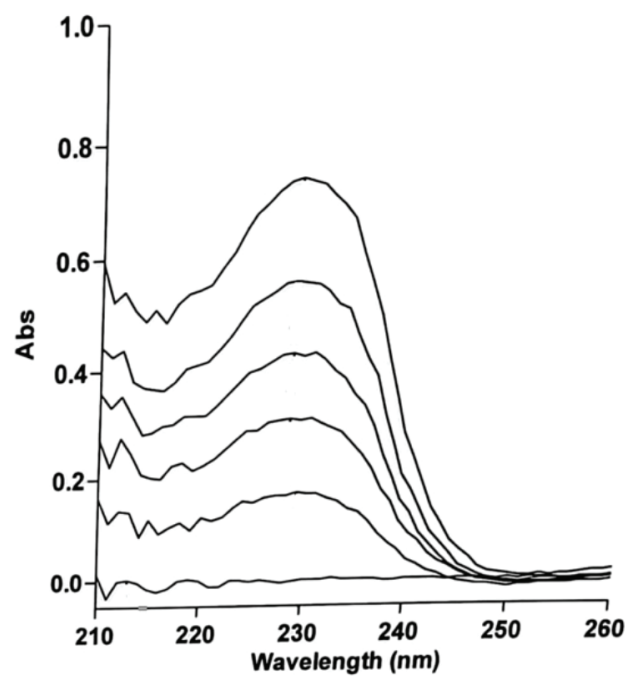

Figure 2B. Overlapped linearity graphs of UV-spectroscopic method
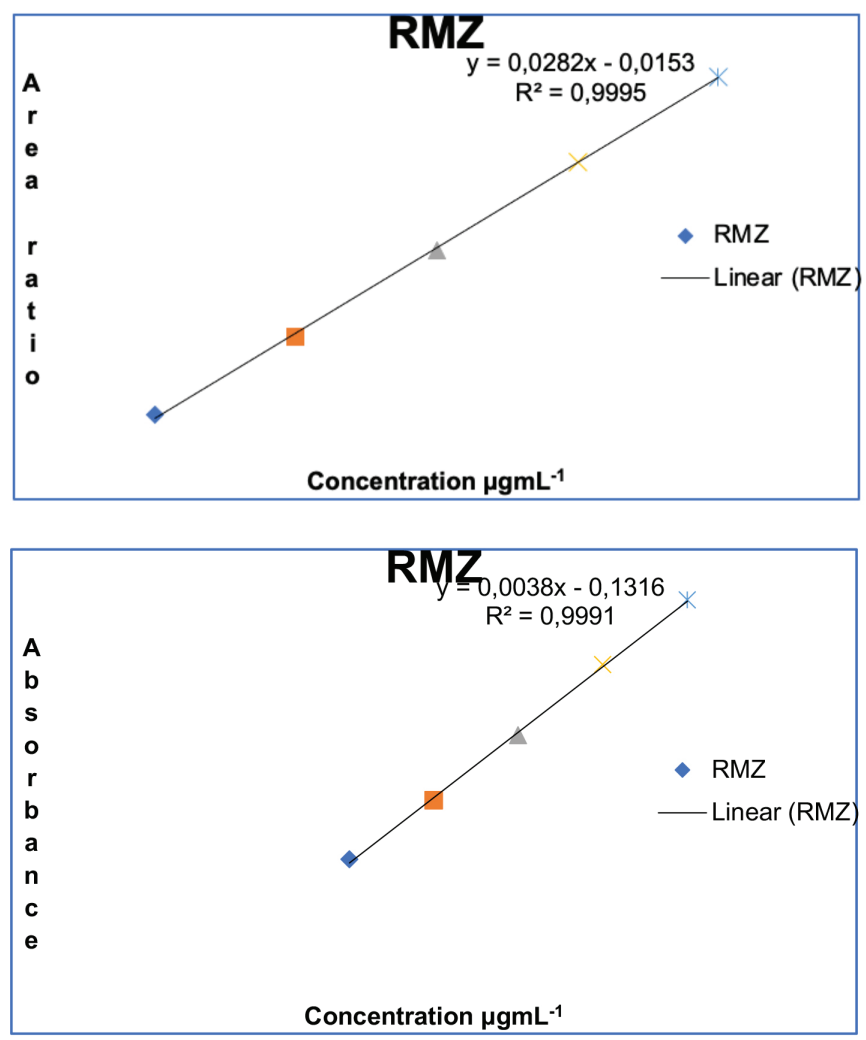

Figure 3. Linearity graphs plotted by RP-HPLC data (A) and UV-visible spectroscopy data (B)
In case of HPLC method, RMZ and ATST peaks were eluted at different time intervals. The working standard solutions of RMZ ranging between $10 \mu \mathrm{g} \mathrm{mL}^{-1}$ to $50 \mu \mathrm{g} \mathrm{mL}^{-1}$ were eluted along with the internal standard ATST. The concentration of the ATST was fixed at $30 \mu \mathrm{g} \mathrm{mL}^{-1}$. The linearity graph was plotted by taking the values of the peak area ratio of RMZ to ATST. With the resulting straight line obtained from the linearity graph as shown in Figures $3 A$ and $B$, we could validate the precision of the analyst using this method. The regression coefficient $\left(R^{2}\right)$ value was found to be more than 0.999 , following the equation $Y=M X+C$. The results are tabulated in Table 3.

\section{Recovery}

This parameter shows that the study of accuracy estimation accomplished by the standard solution of the lower, middle, upper and blank, spiked at 60,80 , and $120 \%$ against $100 \%$. The results were calculated using the standard procedures and the recovery data were found to be satisfactory. The values were shown in Table 4. The accepted limits of recovery were in the range of $98-102 \%$. All the observed outcomes were within the range. Hence, the proposed method can be adopted in industry units and in educational labs for the assay of RMZ.

The recovery parameter in spectroscopic method was performed by the standard solution of the lower, middle, upper and blank, spiked at 60,80 , and $120 \%$ against $100 \%$. The outcomes were found to be satisfactory. The results are tabulated in Table 4.

\section{Precision}

Precision results of the developed methods were found to be good and in compliance with $\mathrm{ICH}$ guidelines. Based on the results of the precision parameter, the HPLC method was found to be precise. The results are revealed in Table 4. Repeatability testing was performed by six individual spikes. The outcomes of inter-day and intra-day analysis revealed that there was not much deviation in the results and RSD\% was found to be less than $2.0 \%$. Therefore, the system suitability of the proposed HPLC method was excellent and thereby precision of the system. The results are shown in Table 4.

In the spectroscopic method, intra-day and inter-day precision was studied by estimating the consistent responses at three different time intervals on the same day and on three different days by taking different working standard solutions. The percentage of RSD was found to be less than $2.0 \%$ i.e., 0.96 , and 0.85 for the intraday and inter-day, respectively, which indicates good reproducibility. These results, which are tabulated in Table 4, indicated that the precision of the UV spectroscopic method is good.

\section{Robustness studies}

The robustness of the HPLC method was studied by a slight deviation in the boosted conditions of the method by injecting a solution of a known concentration. The distinctive conditions correspond to variation of flow rate in the mobile phase ranging

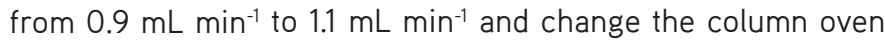
temperature at $25^{\circ} \mathrm{C}$ and $30^{\circ} \mathrm{C}$. The results are tabulated in Table 5, which revealed that robustness values are satisfactory and there was not much variance in results and therefore, 
Table 4. Recovery and precision data

\begin{tabular}{|c|c|c|c|c|c|c|c|c|}
\hline \multirow[t]{2}{*}{ Concentration } & \multirow[t]{2}{*}{ Amount of the drug is taken } & \multicolumn{4}{|c|}{ RP-HPLC } & \multicolumn{2}{|c|}{ UV spectroscopy } & \multirow{2}{*}{$\begin{array}{l}\text { Limit } \\
-\end{array}$} \\
\hline & & $\mathrm{RMZ}$ & $\%$ RSD* & ATST & $\%$ RSD* & RMZ & $\% \mathrm{RSD}^{* *}$ & \\
\hline $60 \%$ & $60 \mathrm{mg} \mathrm{mL}^{-1}$ & 99.50 & 0.95 & 101.00 & 0.60 & 98.50 & 0.85 & $98 \%-102 \%$ \\
\hline $80 \%$ & $80 \mathrm{mg} \mathrm{mL}^{-1}$ & 99.00 & 0.82 & 99.00 & 0.65 & 98.80 & 0.92 & $98 \%-102 \%$ \\
\hline $120 \%$ & $120 \mathrm{mg} \mathrm{mL}^{-1}$ & 98.50 & 0.75 & 99.50 & 0.74 & 99.50 & 0.97 & $98 \%-102 \%$ \\
\hline Intraday & & & 0.65 & & 0.72 & & 0.96 & NMT-2.0 \\
\hline Interday & & & 0.59 & & 0.65 & & 0.85 & NMT-2.0 \\
\hline
\end{tabular}

*Average of 6 injections, **Average of 6 scans, RSD: Relative standard deviation, RMZ: Remogliflozin etabonate, UV: Ultraviolet, ATST: Atorvastatin

Table 5. Robustness evaluation parameters

\begin{tabular}{llll} 
Parameter & Variations & RMZ retention time & ATST retention time \\
\hline \multirow{3}{*}{ Flow rate } & $1.9 \mathrm{~mL} \mathrm{~min}^{-1}$ & 6.45 & 7.32 \\
\cline { 2 - 4 } & $2.0 \mathrm{~mL} \mathrm{~min}^{-1}$ & 6.10 & 7.00 \\
\hline \multirow{2}{*}{ Temperature } & $2.1 \mathrm{~mL} \mathrm{~min}^{-1}$ & 5.85 & 6.64 \\
\hline
\end{tabular}

RMZ: Remogliflozin etabonate, ATST: Atorvastatin

Table 6. Assay results

\begin{tabular}{|c|c|c|c|c|c|}
\hline Name of the drug & Instruments & $\begin{array}{l}\text { Label claims of } \\
\text { market sample in } \mathrm{mg} \\
\text { per tablet }\end{array}$ & $\begin{array}{l}\text { Obtained result } \\
\text { in } \mathrm{mg} \text { per tablet }\end{array}$ & $\begin{array}{l}\text { Assay } \\
\text { values (\%) }\end{array}$ & Limit \\
\hline \multirow{2}{*}{ RMZ } & HPLC & 200 & 199 & 99.5 & $98.00 \%-102 \%$ \\
\hline & UV spectroscopy & 200 & 197 & 98.5 & $98.00 \%-102 \%$ \\
\hline
\end{tabular}

HPLC: High performance liquid chromatography; RMZ: Remogliflozin etabonate, UV: Ultraviolet

the projected method can be used under different conditions. However, in the case of UV spectroscopic method, the robustness parameter was performed by a slight modification in the detection wavelength by $\pm 2 \mathrm{~nm}$ and outcomes were found to be satisfactory.

\section{Ruggedness}

In the ruggedness parameter, standard working solutions were examined by the same chromatographic system on different days using the same column. It was observed from the results that there was a small variation in the peak area and there were no large differences in the RT. The percentage of RSD was found to be less than $2.0 \%$ for RMZ. The resulting data revealed that the developed method is rugged. In the alternate days, the same detector responses were observed and it was successfully found that the projected method is capable of achieving results with great precision on different days. Also, ruggedness was determined using different HPLC instruments by injecting a known concentration of a solution. The detector response, good reproducibility, and no variations in RT indicated that the method is fundamentally rugged. In the spectroscopic method, the ruggedness parameter was examined using different concentrations of the solution and a slight change in the wavelength. The percentage of RSD did not diverge much with the absorbance value. Hence, the developed method was rugged and can be adopted for the assay of RMZ.

\section{Specificity}

Assay

This parameter was carried out by successive separation of RMZ and ATST, which was established against placebo, which contains potential excipients. In the assay parameter, sss interference found and both peaks were sharp and separated at the baseline. It was found that no interference of the excipients in the test solution. Therefore, the projected HPLC method was established specifically. The obtained results were found to be satisfactory and are shown in Table 6.

In the case of the spectroscopic method, no interferences were found by the placebo of tablet formulations. Thus, the obtained results were acceptable and the results are shown in Table 6.

\section{DISCUSSION}

Most of the diabetic drug formulations contain pro-drug of gliflozin derivatives like RMZ to prevent diabetic disorder. 
Several formulations of the diabetic drug contain gliflozin derivative drugs. The literature survey revealed that few analytical methods have been developed and validated for the determination of RMZ, viz., UPLC, HPLC and UV spectroscopic methods. But most of these methods have one or the other drawbacks. For example, the UPLC is very expensive and hence small-scale industries and laboratories cannot afford. Some HPLC and UV spectroscopic methods were developed for the determination of pro-drugs of gliozzi but not included RMZ. Through statistical data analysis (Table 1) of the reported methods, it was planned to develop and validate HPLC and UV spectroscopic methods for the assay of RMZ. These analytical methods are simple, sensitive, rapid, rugged, use inexpensive chemicals, involve small sample volumes, and show good recovery. The results of the parameters comply with $\mathrm{ICH}$ guidelines.

\section{CONCLUSION}

A few RP-HPLC methods have been developed for the determination of gliozzi derivatives such as canagliflozin, empagliflozin, and metformin hydrochloride. These methods were carried out for the determination of either one or two of the above-mentioned drugs or a single drug along with other combinations. The projected methods are distinctive from the reported methods. In RP-HPLC method, the total run time was $10 \mathrm{~min}$. The linearity range for RP-HPLC method was found to be from $10 \mu \mathrm{g} \mathrm{mL}^{-1}$ to $50 \mu \mathrm{g} \mathrm{mL}^{-1}$ and for the UV spectroscopic method, it was found to be in the range of 100 to $250 \mu \mathrm{g} \mathrm{mL}^{-1}$. The values of regression coefficients $\left(R^{2}\right)$ were found to be more than 0.999 for both techniques. The LOD and LOQ values for the UV and HPLC methods were found to be $10.0 \mu \mathrm{g} \mathrm{mL}^{-1}$ and $1.0 \mu \mathrm{g}$ $\mathrm{mL}^{-1}$ and $40 \mu \mathrm{g} \mathrm{mL}^{-1}$ and $3.5 \mu \mathrm{g} \mathrm{mL}^{-1}$, respectively. The developed methods were found to be simple, accurate, reproducible and precise. The obtained data of both the methods clearly showed that RP-HPLC method was relatively more sensitive than the UV spectroscopic method.

\section{Ethics}

Ethics Committee Approval: The ethics committee approval not required for the proposed research. We were not used any kind of human being and animal matrices.

Informed Consent: Not applicable

\section{Authorship Contributions}

Concept: M.D.H., Design: M.D.H., Data Collection or Processing: N.I., Analysis or Interpretation: B.C.Y., M.D.H., Literature Search: K.S.C., Writing: N.I., M.D.H., B.C.Y.,

Conflict of Interest: No conflict of interest was declared by the authors.

Financial Disclosure: The authors declared that this study received no financial support.

\section{REFERENCES}

1. Tammisetty MR, Challa BR, Puttagunta SB. A novel analytical method for the simultaneous estimation of remogliflozin and metformin hydrochloride by UPLC/PDA in bulk and formulation application to the estimation of product traces. Turk J Pharm Sci. 2021;18:296-305.

2. Hussey EK, Kapur A, O'Connor-Semmes R, Tao W, Rafferty B, Polli JW, James CD Jr, Dobbins RL. Safety, pharmacokinetics and pharmacodynamics of remogliflozin etabonate, a novel SGLT2 inhibitor, and metformin when co-administered in subjects with type 2 diabetes mellitus. BMC Pharmacol Toxicol. 2013;14:25.

3. Padmaja N, Babu Sharath M, Veerabhadram G. Development and validation of UV spectrophotometric method for simultaneous estimation of empagliflozin and metformin hydrochloride in bulk drugs and combined dosage forms. Sch Res J. 2016;8:207-213.

4. Pandit V, Pai RS, Devi K, Singh G, Narayana S, Suresh S. Development and validation of the liquid chromatographic method for simultaneous estimation of metformin, pioglitazone, and glimepiride in pharmaceutical dosage forms. Pharm Methods. 2012;3:9-13.

5. Aswini R, Eswarudu MM, Babu PS. A novel RP-HPLC method for simultaneous estimation of dapagliflozin and saxagliptin in bulk and pharmaceutical dosage form. Int J Pharm Sci Res. 2018;12:5161-5167.

6. Caglar S, Alp AR. A Validated high performance liquid chromatography method for the determination of saxagliptin and metformin in bulk. A stability indicating study. J Anal Bioanal Tech. 2014;12(Suppl):1-5.

7. Prasad PBN, Satyanarayana K, Krishnamohan G. Development and validation of a method for simultaneous determination of metformin and saxagliptin in formulation by RP-HPLC. Am J Analyt Chem. 2015;5:737742.

8. Kommineni V, Chowdary KP, Prasad SM. Development of a new stability indicating RP-HPLC method for simultaneous estimation of metformin hydrochloride and canagliflozin and its validation as per $\mathrm{ICH}$ guidelines. Int J Pharm Sci Res. 2017;8:3427-3435.

9. D'Douza S, Muddu K, Gude Sai S, Vasantharaju SG. Stability indicating assay method development and validation to simultaneously estimate metformin hydrochloride and canagliflozin by RP-HPLC. Curr Trends Biotechnol Pharm. 2016;10:334-342.

10. Ayoub BM. Development and validation of simple spectrophotometric and chemometric methods for simultaneous determination of empagliflozin and metformin: Applied to recently approved pharmaceutical formulation. Spectrochim Acta Part A Mol Biomol Spectros. 2016;168:118-122.

11. Attimarad M, Nair AB, Sreeharsha N, Al-Dhubiab BE, Venugopala $\mathrm{KN}$, Shinu P. Development and validation of green UV derivative spectrophotometric methods for simultaneous determination metformin and remogliflozin from formulation: evaluation of greenness. Int J Environ Res Public Health. 2021;18:448.

12. International Council of Harmonization. Q2B Validation of analytical procedures: methodology and availability. Federal Register; 1997. https://www.fda.gov/media/71725/download 